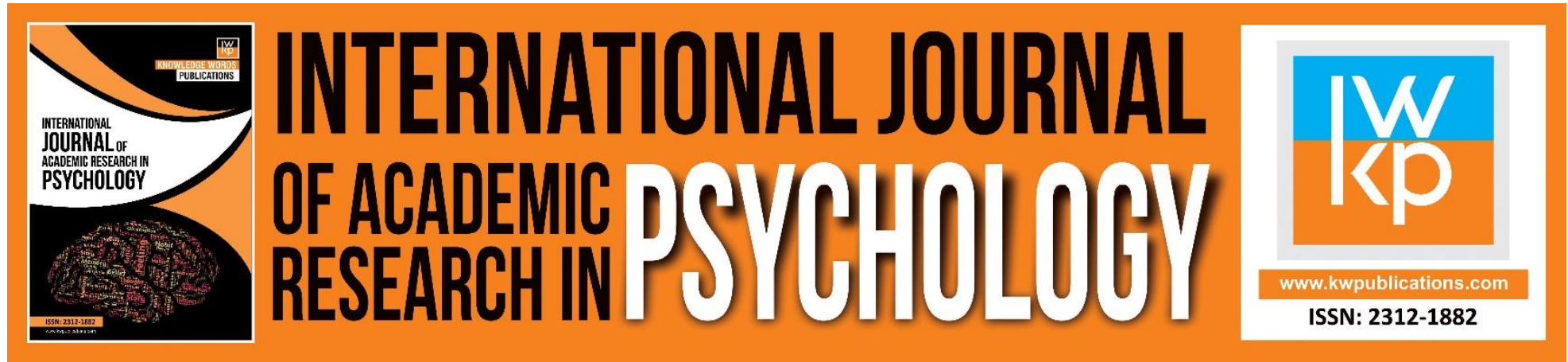

\title{
Depression of Women Undergoing Divorce Process in Malaysia
}

\section{Nur Azmina Paslan, Mohamad Hashim Othman}

To Link this Article: http://dx.doi.org/10.46886/IJARP/v6-i1/6979

DOI:10.46886/IJARP/v6-i1/6979

Received: 01 June 2019, Revised: 13 July 2019, Accepted: 16 August 2019

Published Online: 30 August 2019

In-Text Citation: (Paslan \& Othman, 2019)

To Cite this Article: Paslan, N. A., \& Othman, M. H. (2019). Depression of Women Undergoing Divorce Process in Malaysia. International Journal of Academic Research in Psychology, 6(1), 41-48.

Copyright: (C) 2019 The Author(s)

Published by Knowledge Words Publications (www.kwpublications.com)

This article is published under the Creative Commons Attribution (CC BY 4.0) license. Anyone may reproduce, distribute, translate and create derivative works of this article (for both commercial and non-commercial purposes), subject to full attribution to the original publication and authors. The full terms of this license may be seen

at: http://creativecommons.org/licences/by/4.0/legalcode

\section{Vol. 6, No. 1, 2019, Pg. 41 - 48}

Full Terms \& Conditions of access and use can be found at https://kwpublications.com/pages/detail/publication-ethics 


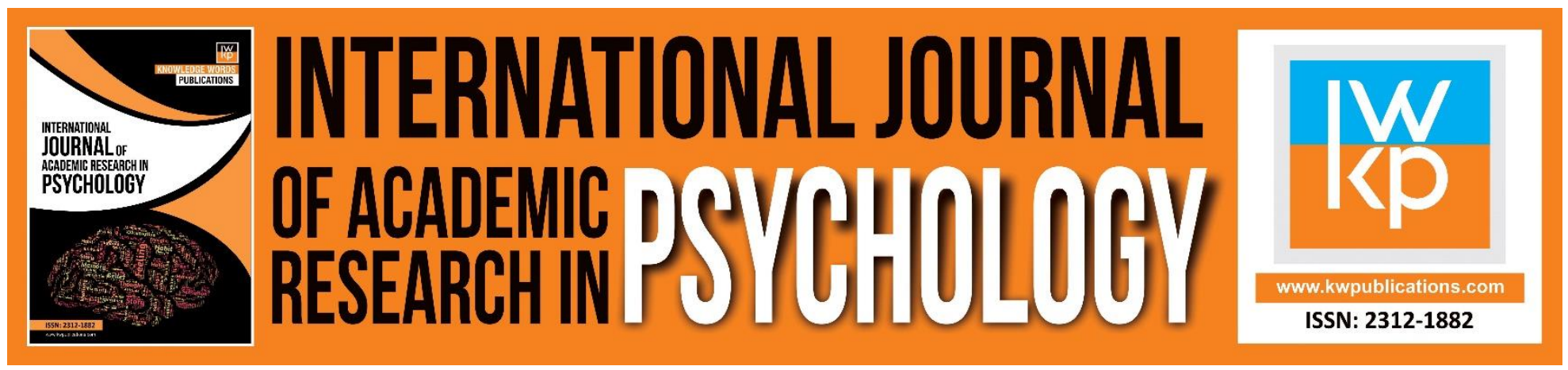

\title{
Depression of Women Undergoing Divorce Process in Malaysia
}

\author{
Nur Azmina Paslan, Mohamad Hashim Othman \\ School of Educational Studies, Universiti Sains Malaysia, Penang, Malaysia \\ Email: nurazminapaslan.law@gmail.com
}

\begin{abstract}
The aims of this study are to identify the level of depression among women undergoing the divorce process. The sample was chosen through the purposive sampling technique among women that undergoing the divorce process in Malaysia. Qualitative data were collected through the Beck Depression Inventory-II (BDI-II). The data were then analysed through descriptive analysis. The results showed the reduction in depression levels after the women undergoing the divorce process go through counseling intervention sessions. In conclusion, it is shown that counseling intervention sessions were effective in reducing depression levels among women undergoing the divorce process.
\end{abstract} Keywords: Depression, Women, Divorce, Counseling, Malaysia.

\section{Introduction}

According to Hariri \& Raihanah (2014) stated that marriage includes trust and responsibilities that need to be implemented by the married couple through legal marriage as allowed by Islamic religous. Based on Hamzah \& Jasmi (2020), a long-lasting marriage is an aim for the married couple as the husband and wife need to be ready to hold the responsibilities in marriage life.

Divorce among Malays in Malaysia shown an alarming increase as 1/3 divorce cases happened in the first five years in a marriage. Divorce definitely gave negative effects to the family members and leads to poor relationship quality between a parents and the children. According to Marziah \& Salina (2019) stated that past researches found that married individual that was not happy with the marriage experienced negative effects such as health problems. This situation also gave huge impacts toward the family and their careers. Unhappy and poor quality marriage will largely impact the childrens' welfare along with their emotional and mental growth too.

\section{Literature Review}

Conflict, neglect of responsibilities, and abuse are factors that lead to divorce. In fact, divorce was used as a solution to marriage problems. Divorce at the West especially Europe and United States focus on factors like demography aspect and the effects of divorce toward the adults and the children. 
INTERNATIONAL JOURNAL OF ACADEMIC RESEARCH IN PSYCHOLOGY

Vol. 6, No. 1, 2019, E-ISSN: 2312-1882 @ 2018 KWP

Divorce can increase the risk of mental health problems among adults and children (Amato \& James, 2010).

According to Shamsiah \& Walid (2014) stated that continuous and long duration of marriage's conflicts can lead to stress. Continuous stress lead to mental health problems such as depression symptoms. Women with depression tend to have psychological dysfunctional, low self-appreciation and would likely avoid social interaction. Conflicts involving marriage were also affected the couple's psychological welfare.

This shown that depression issue among women undergoing divorce process is serious and appropriate interventions are needed to treat depression symptoms among them, involving psychological, cognitive, emotional and behavioural aspects to become normal and continue living and hold responsibilities of their children. According to Aziz (2019) stated that Mental Health Organization (United States) estimated that 54 out of 400 million Americans have mental health problems due to factors such as depression, bipolar disorder, schizophrenia and post-traumatic stress depression.

According to Beck (2008), Cognitive Behavioral Therapy can provide cognitive awareness that leads to an individual's behaviour and emotional changes. This showed that an individual's automatic thinking is caused by negative cognitive distortion and affecting an individual's mind then affects behaviour and emotional functioning.

Based on See Mey \& Siew (2005) stated that cognitive restructuring is needed to return the mind functional caused by negative mind distortion. Counseling intervention sessions using Cognitive Behavioural Therapy is one of the main interventions. Most therapists applied this technique to restructure the client's behavioural aspect along with the cognitive restructuring process toward negative mind distortion that affecting the client. Behavior Cognitive Theory has two types of model theories which are behavioural theory and cognitive theory (Payne, 2005). The behavioural model needs to focus on behavioural changes and the client's actions while the cognitive model focuses on changes or the client's mind restructure.

\section{Objectives}

The objectives of this study are

3.1 To determine the depression level among women undergoing the divorce process

3.2 To test the effect of counselling intervention sessions in reducing the depression among women undergoing the divorce process

\section{Methodology}

This instrument consists of questions related to depressive symptoms such as losing hope and physical symptoms such as fatigue, weight loss and loss of interest in sex. 
INTERNATIONAL JOURNAL OF ACADEMIC RESEARCH IN PSYCHOLOGY

Vol. 6, No. 1, 2019, E-ISSN: 2312-1882 @ 2018 KWP

Table 1.1 Beck Depression Inventory-II (BDI-II)

$\begin{array}{ll}0 & \text { I do not feel sad } \\ 1 & \text { I feel sad much of the time } \\ 2 & \text { I am sad all the time } \\ 3 & \text { I am so sad or unhappy that I can't stand it }\end{array}$

Table 1.2 Item for Beck Depression Inventory-II (BDI-II)

$\begin{array}{ll}\text { Item 1-13 } & \text { Natural Psychological Symptoms } \\ \text { Item 14-21 } & \text { Physical Symptoms }\end{array}$

Table 1.3: Evaluation Score of Beck Depression Inventory-II (BDI-II)

\begin{tabular}{ll}
\hline Score & Depression Level \\
\hline $0-13$ & Minimum depression \\
$14-19$ & Mild depression \\
$20-28$ & Moderate depression \\
$29-63$ & Critical depression \\
\hline
\end{tabular}

The main objective of the new version (BDI-II) is to comply with all the diagnostic criteria for depression where there are added items, omitted and word replacement to evaluates the depression symptoms accurately as listed in DSM-IV and to also increase the content validity. The differences between Beck Depression Inventory-I and Beck Depression Inventory-II can also be seen in the specific items such as item No. 16 that is about sleeping patterns and item No. 18 that related to eating patterns that have significant differences with the scale rated as $0,1 \mathrm{a}, 1 \mathrm{~b}, 2 \mathrm{a}, 2 \mathrm{~b}, 3 \mathrm{a}$, and $3 \mathrm{~b}$.

Table 1.4 Beck Depression Inventory-II (BDI-II) for item No.16

\begin{tabular}{ll}
\hline 0 & I have not experienced any change in my sleeping \\
1a & I sleep somewhat more than usual \\
1b & I sleep somewhat less than usual \\
$2 a$ & I sleep a lot more than usual \\
$2 b$ & I sleep a lot less than usual \\
$3 a$ & I sleep most of the day \\
$3 b$ & I wake up 1-2 hours early and can't get back to sleep
\end{tabular}


INTERNATIONAL JOURNAL OF ACADEMIC RESEARCH IN PSYCHOLOGY

Vol. 6, No. 1, 2019, E-ISSN: 2312-1882 @ 2018 KWP

Table 1.5

$0 \quad$ I have not experienced any change in my appetite

1a My appetite is somewhat less than usual

1b My appetite is somewhat greater than usual

2a My appetite is much less than before

$2 b \quad$ My appetite is much greater than usual

3a I have no appetite at all

3b I crave food all the time

There were a few researches in the West that used the Beck Depression Inventory-II. BDI-II was used among adult clinical patients with chronic depression (Andrew et. al., 2014). There was also research that used BDI-II to measure depression level among women after giving birth. BDI-II needs to be used carefully among these women because of the significant emotional and physical changes. The result showed that women that recently gave birth have a high score in BDI-II and experienced depression symptoms such as sleeping pattern changes and fatigue. Furthermore, they tend to have negative cognitive symptoms such as high self-criticism and self-judgement (Elisabeth et al., 2012).

\section{Findings}

The quantitative analysis results were retrieved from the Beck Depression Inventory-II (BDI-II) that was given to clients on pre-session, second session, fourth session and sixth session. The data analysis scores are as shown below:

Table 1.6: BDI-II Score

\begin{tabular}{lllll}
\hline Test & $\begin{array}{l}\text { Score } \\
\text { Values }\end{array}$ & $\begin{array}{l}\text { Score } \\
\text { Differences }\end{array}$ & $\begin{array}{l}\text { Percentage } \\
\text { Differences (\%) }\end{array}$ & Depression Levels \\
\hline Pre-test & 45 & - & & Critical Depression \\
Post 1 & 38 & 7 & 11.11 & Critical Depression \\
Post 2 & 27 & 11 & 17.46 & Moderate Depression \\
Post 3 & 15 & 12 & 19.04 & Low Depression \\
\hline
\end{tabular}

Table 1 shows the scores, score differences, percentage differences and depression levels experienced by the clients before and after undergoing counselling intervention sessions. Clients' BDI-II score before counseling session interventions is at 45 which is at the critical depression level. Post 1 test shows the decreasing of the score value of BDI-II at 38 although it is still at a critical depression level. Post 2 test shows a decreasing score value of BDI-II at 27 which is at a moderate depression level. The decreasing of BDI-II score in Post 3 test decrease at score 15 that showed clients are at the mild depression level to $47.62 \%$ as shown in Table 1.1. 


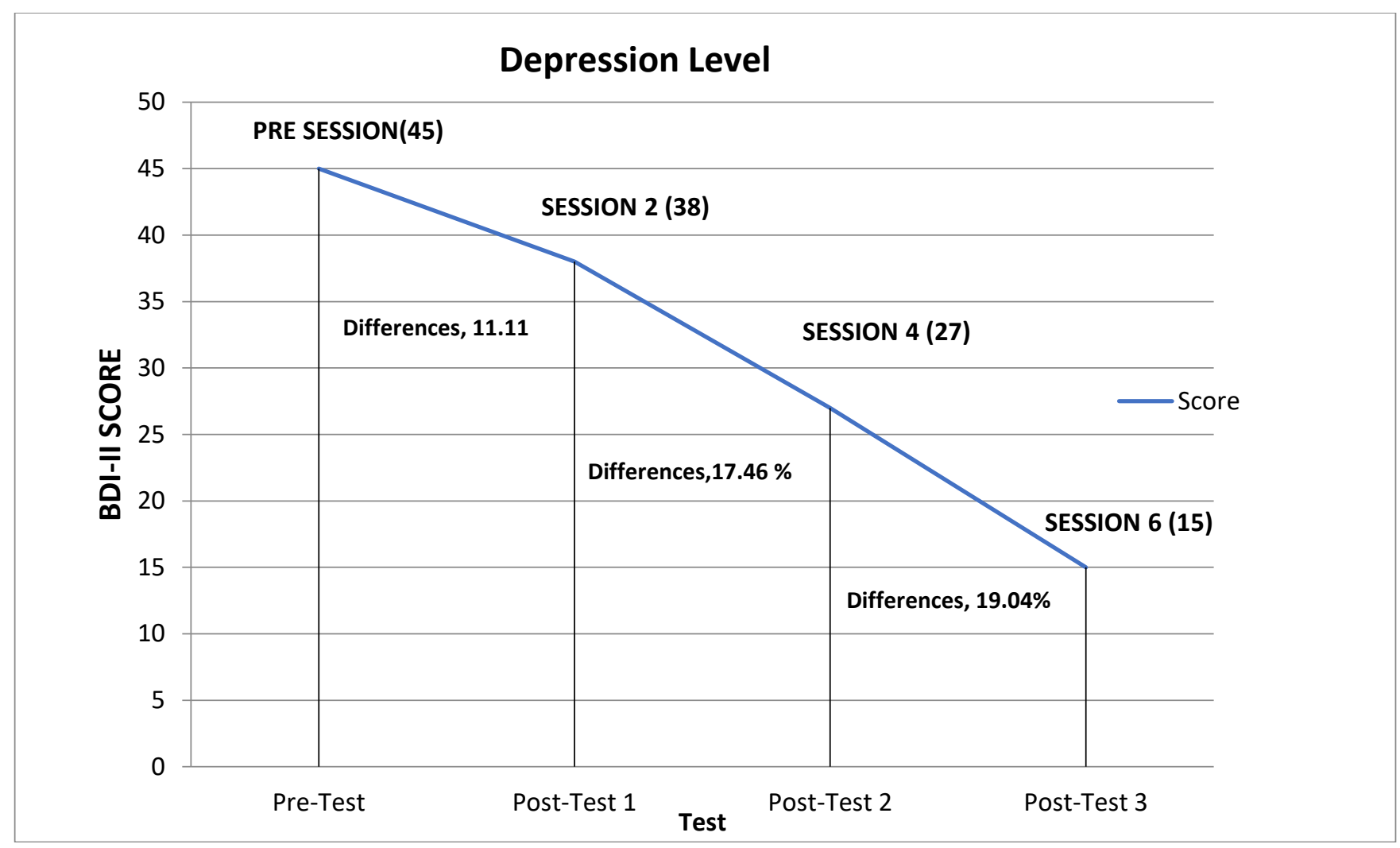

Table 1.7: Score Analysis of BDI-II

Table 1.7 shows depression levels percentages experienced by clients before and after going through counseling intervention sessions. Pre-session shows depression score among the clients is at $71.42 \%$ which indicates critical depression while the second session shows the decreasing percentage score of BDI-II at $60.32 \%$ but still at a critical level. At the end of the sixth session, clients' BDI-II score is at $23.81 \%$ which shows a moderate depression level. Overall, depression experienced by clients shows a reduction of $47.61 \%$.

This reduction was the result of successful counseling intervention sessions. The researcher found that these counseling intervention sessions suited with the time frame of critical depression level experienced by the clients although it was still in control and did not achieve mental stress level that needs treatments from the psychiatrists.

The reduction of clients' depression level is also affected by their commitment in going through the six times counselling intervention sessions. Counselor roles also affected the reduction of depression level as the counselor applied basic counselling skills such as listening skill, consulted and helped clients to get awareness in facing their issues. According to Corey (2009), values held by a counselor enables clients to give cooperation and focusing on the counselling intervention sessions implemented by the respective counselor.

The decreased depression level experienced by the clients showed that these counselling intervention sessions were suitable among women with depression. In fact, the techniques used are suitable for the education level and clients' intellectual. Clients' commitment lead to the decrease of depression level as supported by Jacobson (2000) in his research stated that clients that completed the tasks showed changes in their depression compared to the clients that did not give commitment. 
INTERNATIONAL JOURNAL OF ACADEMIC RESEARCH IN PSYCHOLOGY

Vol. 6, No. 1, 2019, E-ISSN: 2312-1882 @ 2018 KWP

\section{Discussion \& Conclusion}

Individual counseling intervention session is a systematic process to help an individual based on the basic helping relationship principles by a registered counselor so that the process can achieve a change, improvement and holistic, good and voluntary improvement in client's self dan continuously throughout their life. Individual counselling is a professional relationship between a counselor and a client. This counseling process involves a developmental sequence relationship between a counselor and a client in a certain time frame. This relationship starts from a level and keeps developing to another levels. According to Mizan \& Mokhtar (2005); Khalid, Islam \& Ahmed (2019); Alzgool (2019); Muhammad et al., (2019), these levels are conducted systematically with an objective or certain means.

Barber \& DeRubeis (2001) stated that Cognitive Behavior Therapy approach in counseling intervention sessions toward the individual with depression for 12 weeks showed that the depression symptoms have cognitive changes based on the Attributional Style Questionnaire, Depression Anxiety Stress and thought-listing using Ways of Responding Questionnaire measurements. According to researches, an effective cognitive-behavioral approach in counselling intervention sessions can overcome depression problems, anxiety, panic, stress, and others 80 negative emotions that related to the poor internal locus control problems.

Research by Malkinson (2001) had proved that the cognitive behavioural approach had successfully overcome individuals' grief problems where they showed an increased self-belief compared to the past where they were easily influenced by external factors. Counselor needs to believe that clients' mind changes will impact clients' behavioural changes. Cognitive behavioural theory as a therapeutic procedure focuses on emotion and thinking changes but in other dimension, its main purpose is to adapt to certain behavioural changes (Payne, 2005).

In conclusion, this research has answered the research objectives to measure depression level among women the undergoing divorce process and the effect of counselling intervention sessions in reducing the depression level.

\section{References}

Amato, P. R., \& Alan, B. (2001). The Legacy of Parent's Marital Discord: Consequences for Children's Marital Quality. Journal of Personality \& Social Psychology. 81(4), 627-638.

Amato, P. R., \& Sobolewski, J. M. (2001). The Effect of Divorce and Marital Discord on Adult Children's Psychological Well-Being. American Sociological Review, 66(6), 900-921. JStore database.

Addis, M., \& Jacobson, N. (2000). A Closer Look at the Treatment Rational and Homework Compliance in Cognitive-Behavioral Therapy for Depression. Cognitive Therapy and Research, 24, 313-326.

Andrew, J., Cherlin, P., Lindsay C. L., \& Christine, M. R. (1997). Effects of Divorce on Mental Health through the Life Course. Harris Graduate School of Public Policy Studies University of Chicago.

Alzgool, M. (2019). Nexus between Green HRM and Green Management towards Fostering Green Values. Management Science Letters, 9(12), 2073-2082.

Aziz, M. S. (2019). Neo-Cognitive Behavioral Therapy. I Psychology and Counseling Academy. Malaysia. 
INTERNATIONAL JOURNAL OF ACADEMIC RESEARCH IN PSYCHOLOGY

Vol. 6, No. 1, 2019, E-ISSN: 2312-1882 @ 2018 KWP

Barber, J. P., \& DeRubeis, R. J. (2001). Change in Compensatory Skills in Cognitive

Therapy for Depression. Journal of Psychotherapy Practice Research. (10), 8-13.

Bond, T., \& Grainne, G. (2010). Ethical Framework for Good Practice in Counselling and Psychotherapy. British Association for Counselling and Psychotherapy. Tarikh capaian: 20 Mei 2017.

Corey, G. (2005). Theory and Practice of Counseling and Psychotherapy. USA: Thomsom Bookstore.

Cully, J. A., \& Teten, A. L. (2008). A Therapist's Guide to Brief Cognitive Behavioral Therapy. Department of Veterans Affairs South Central MIRECC. Houston.

Creswell, J. W. (2014). Research Design. Qualitative, Quantitative \& Mixed Methods Approaches. SAGE Publications, Inc.

Ching, S. M., \& Siew, L. S. (2005), Depression Among Students: Single Case Study. Education Journal. Malaysian of Science University. Volume: 20. 113-129.

Islamic Family Law. (Penang State) (2004). Penang Islamic Religious Council.

Frank, E., Furstenberg \& Kathleen, E. K. (2001). Delayed Parental Divorce: How Much Do Children Benefit? Marriage and Family. (63), 446-457

Gay, L. R., \& Airasian, P. (2000). Educational Research: Competencies for Analysis and Application. New Jersey: Pearson Education.

Helbig, S., \& Lydia, F. (2004). Clinical Psychology and Psychotherapy. Problems with homework compliance in CBT: Rare exception or rather frequent? Behavioural and Cognitive Psychotherapy. ResearchGate database.

Hariri, M. S., \& Raihanah, A. (2014). Reinforcement of Family Institution through Divorce Control: Literature Analysis. Fiqh Journal, No. 11 (2014) 175-194.

Hamzah, N. J., \& Kamarul, A. (2020). Career Women According to Islamic Perspective. Skudai, Johor: UTM Press Publisher.

Khalid, N., Islam, D. M. Z., \& Ahmed, M. R. M. (2019). Sentrepreneurial Training and Organizational Performance: Implications for Future. Humanities \& Social Sciences Reviews, 7(2), 590-593.

Kwon, S., \& Oei, T. P. S. (2003). Cognitive Change Processes in a Group Cognitive Behavior Therapy of Depression. Journal of Behavior Therapy and Experimental Psychiatry. (34), 73-85.

Marziah, S. Z., Rahman, A. B., Ba'yah, A. K., \& Salina, N. (2018). Measurement and Predictor of a Quality Marriage: A Review. Journal of Education and Social Sciences 9 (1): 5964.

Muhammad, K., Saoula, O., Issa, M., \& Ahmed, U. (2019). Contract Management and Performance Characteristics: An Empirical and Managerial Implication for Indonesia. Management Science Letters, 9(8), 1289-1298.

Paulo, K., \& Aaron, T. B. (2008). Cognitive Therapy: Foundations, Conceptual Models, Applications and Research. 30 (Supp II). S54-64.

Pang, Y. W., \& Gorenstein, C. (2012). Psychometric Properties of the Beck Depression Inventory-II. A Comprehensive Review. Brazil.

Shamsiah, M. S., \& Walid, A. H. (2012). Mental Depression in Fasakh. Observation in Practice and Procedure in Malaysia. Malaysian Islamic Understanding Institute. 